\title{
New advancements and developments in treatment of renal cell carcinoma: focus on pazopanib
}

This article was published in the following Dove Press journal:

OncoTargets and Therapy

18 September 2010

Number of times this article has been viewed

\author{
C Lance Cowey' \\ Guru Sonparde 2 \\ Thomas E Hutson' \\ 'Baylor-Sammons Cancer Center/ \\ Texas Oncology, PA, GU Oncology \\ Program, Dallas, ${ }^{2}$ Baylor College \\ of Medicine/Texas Oncology, PA, \\ Houston, Texas, USA
}

\begin{abstract}
With the recent approval of pazopanib, an oral multitargeted tyrosine kinase inhibitor which potently targets vascular endothelial growth factor receptors 1-3, platelet-derived growth factor, and c-kit, six agents are now available for use in the management of metastatic renal cell carcinoma (RCC). Pazopanib has shown improved progression-free survival compared with placebo in treatment-naïve or cytokine-treated patients with metastatic RCC in large Phase II and Phase III clinical trials. Pazopanib has demonstrated a tolerable side effect profile and is currently being compared with sunitinib in a Phase III noninferiority trial. In this review, the outcomes of the clinical testing of pazopanib are discussed, as well as a perspective on the placement of pazopanib among other approved agents.

Keywords: renal cell carcinoma, targeted agents, vascular endothelial growth factor inhibitors, pazopanib
\end{abstract}

\section{Introduction}

The number of treatment options for the management of renal cell carcinoma (RCC) has been expanding rapidly. In fact, over the past five years, six new agents have been approved by the US Food and Drug Administration (FDA), markedly expanding the available options for the clinician. Unlike the previous standard of care, immune-based therapies, ${ }^{1}$ these new agents target key molecular pathways which are essential in the pathogenesis of RCC. One vital aspect of RCC molecular biology which has proved to be a very crucial target is that of tumor angiogenesis. ${ }^{2-4} \mathrm{RCC}$ tumors are known to have a highly vascular phenotype, with vascular endothelial growth factor (VEGF) and its effects on the stromal environment playing an important role. ${ }^{5-7}$ Elevated VEGF is commonly noted in RCC patients, ${ }^{8}$ and is felt to be directly related to the functional loss of the von Hippel-Lindau protein which occurs in the majority of sporadic RCC cancers. ${ }^{9,10}$ The von Hippel-Lindau protein regulates hypoxia inducible factors 1 and 2 alpha which in turn are important transcription factors which promote a variety of genes which regulate tumor cell survival, proliferation, and spread. ${ }^{11}$ Several of these genes which are upregulated promote tumor angiogenesis, including VEGF, platelet-derived growth factor (PDGF), and angiopoeitin $2 . .^{10,12}$ Many of the new molecularly targeted agents which have been approved directly inhibit the ability of the RCC to utilize these proangiogenic pathways, such as VEGF and PDGF receptor tyrosine kinase inhibitors (TKIs). ${ }^{13}$

Approved agents which inhibit the VEGF and PDGF receptor tyrosine kinases are sunitinib, sorafenib, and, most recently, pazopanib. Bevacizumab, another improved agent, is a monoclonal antibody which binds the VEGF molecule. Another class of
Correspondence: C Lance Cowey

3535 Worth Street, Dallas,

TX 75246, USA

Email lance.cowey@usoncology.com 
molecularly targeted agents, the mTOR inhibitors, affects the von Hippel-Lindau protein/hypoxia inducible factor pathway at a separate point. mTOR is a protein which is important in regulating cell survival in "stress" conditions, such as low nutrient or oxygen states. One manner in which $\mathrm{mTOR}$ can regulate response to these conditions is by upregulating hypoxia inducible factor protein synthesis. ${ }^{14}$ Currently, the available drugs which target mTOR are temsirolimus and everolimus. Figure 1 illustrates the molecular targets of the currently approved drugs for the management of RCC.

With a variety of treatment options available to the oncologist, it is important to understand the clinical data behind each approved agent and use these data to guide therapeutic decision-making. This current review will describe the preclinical and clinical data involving pazopanib, the latest agent to be approved, with emphasis on this agent's clinical development for RCC. Additionally, a synopsis of other approved agents for RCC will be given in order to help the reader understand the appropriate placement of pazopanib among the available drug options.

\section{Preclinical analysis of pazopanib}

Pazopanib (Votrient ${ }^{\circledR}$, GW786034, [4-[2,3-dimethyl-2Hindazole-6-yl methylamino]2-dypyrimidinyl amino-2methylbenzene sulfonamide]) is a novel multitargeted TKI synthesized by GlaxoSmithKline. The discovery of pazopanib is discussed elsewhere. ${ }^{15}$ By competitively binding to the adenosine triphosphate enzymatic pocket, pazopanib potently inhibits the function of several receptor tyrosine kinases, including VEGF receptors $1-3$, PDGF receptor- $\alpha$ and $-\beta$, and c-kit. ${ }^{16}$ Pazopanib also has modest activity against fibroblast growth factor receptors 1 and 3 and the c-fms receptor. Additionally, pazopanib inhibits 13 other kinases by at least $50 \%$; however, only five of these kinases were inhibited with an $\mathrm{IC}_{50}$ within 10-fold of VEGFR 2 activity (Aurora A, c-RAF, MLK-1, PTK5, and TAO3). Table 1 shows the $\mathrm{IC}_{50}$ inhibition concentrations for kinases clinically relevant to RCC for pazopanib and other similar agents either approved or in development. Although pazopanib does potently inhibit several targets, the range is somewhat narrower than sunitinib and sorafenib.

Pazopanib was found to have inhibitory activity in a variety of human xenografts in preclinical development. ${ }^{16}$

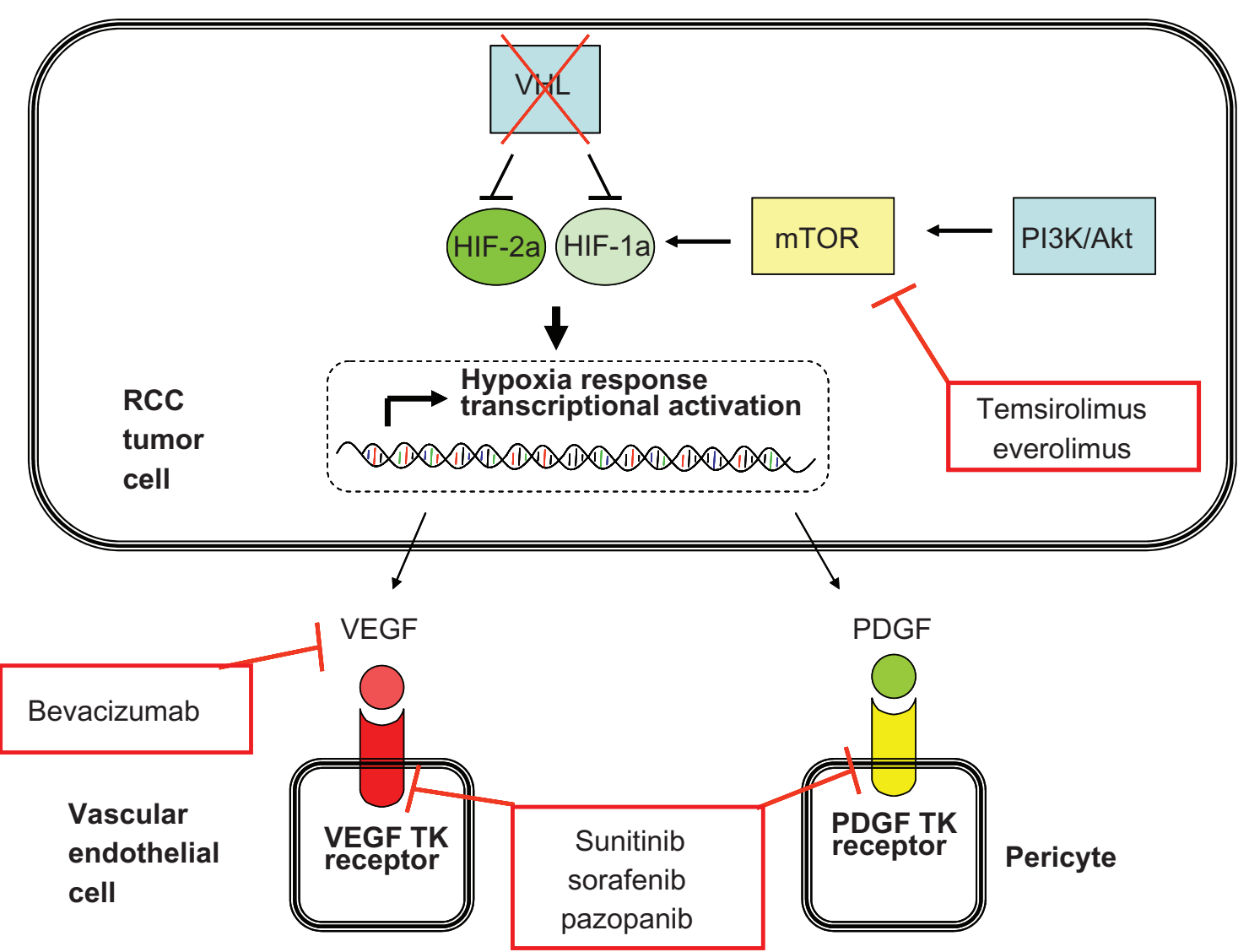

Figure I Key molecular pathways in renal cell carcinoma pathogenesis and the points at which the currently approved agents function.

Abbreviations: HIF, hypoxia inducible factor; RCC, renal cell carcinoma; PDGF, platelet-derived growth factor; TK, tyrosine kinase; VEGF, vascular endothelial growth factor; VHL, von Hippel-Lindau protein. 
Table I Kinase inhibitory concentrations $\left(\mathrm{IC}_{50}\right.$, nmol) for multitargeted tyrosine kinase inhibitors for renal cell carcinoma (includes tivozanib and axitinib which are in Phase III study, but not yet approved) arranged in order of VEGFR2 potency

\begin{tabular}{lllllllll}
\hline Drug & VEGFRI & VEGFR2 & VEGFR3 & PDGF- $\alpha$ & PDGF- $\beta$ & c-kit & FIt-3 & RAF \\
\hline Tivozanib $^{36}$ & 0.21 & 0.16 & 0.24 & - & 1.72 & 1.63 & - \\
Axitinib $^{37}$ & 0.1 & 0.2 & $0.1-0.3$ & 5 & 1.6 & 1.7 & $>1000$ & - \\
Sunitinib $^{38}$ & 2 & 10 & 17 & $5-10$ & 10 & 13 & $1-10$ & - \\
Pazopanib $^{16}$ & 10 & 30 & 47 & 71 & 84 & 74 & $>2000$ & - \\
Sorafenib $^{39}$ & - & 90 & 20 & $50-60$ & $50-60$ & 68 & 46 & $5-10$ \\
\hline
\end{tabular}

Abbreviations: PDGF, platelet-derived growth factor; VEGFR, vascular endothelial growth factor receptor.

The greatest activity was seen in RCC (Caki-2), colorectal (HT29), and non-small cell lung cancer (NCI-H322) xenografts. Of these three tumor types, RCC was the most sensitive to treatment with pazopanib. More modest activity was seen in melanoma (A375p), prostate adenocarcinoma (PC3), and breast adenocarcinoma (BT474) xenograft models. Pazopanib was also shown to inhibit angiogenic activity mediated by VEGF and fibroblast growth factor in two mouse models of angiogenesis. ${ }^{16}$ Of note, pazopanib has been and is currently being evaluated for clinical efficacy in several different tumor types, including breast, cervical, hepatocellular, sarcoma, colorectal, non-small cell lung cancer, malignant glioma, thyroid, and ovarian cancer.

\section{Phase I analysis of pazopanib in advanced solid tumors}

A Phase I study of pazopanib in patients with advanced stage solid tumors whose cancer was refractory to standard therapy was conducted in order to determine the appropriate dosing and safety profile of the agent. In this multicenter, open-label, nonrandomized study, 63 patients were enrolled, with 43 being enrolled to a dose escalation study and 20 evaluated in a dose expansion study. ${ }^{17}$ Patients were required to have histologically confirmed advanced solid tumors, adequate performance status and laboratory parameters, and a life expectancy of $\geq 12$ weeks. The dosing arms that were studied included ranges of 50-100 mg three times weekly, 50-2000 mg daily, and 300-400 mg daily. The optimal dosing regimen was found to be $800 \mathrm{mg}$ daily. Although no maximally tolerated dose was found in this study, a steadystate exposure plateau was reached at the dose of $800 \mathrm{mg}$ daily. Pharmacokinetic analysis showed that the mean halflife of pazopanib was approximately 31 hours. Common drug-related events included hypertension, diarrhea, hair depigmentation, and nausea.

Interestingly, 14 patients obtained some clinical benefit from pazopanib as deemed by either durable ( $\geq$ six months) stable disease or partial response. Three patients obtained a partial response in the study, including two RCC patients and one patient with a pancreatic neuroendocrine tumor. Correlative assessments within the study included dynamic contrast enhanced magnetic resonance imaging in 12 patients. Seven of the 12 patients had a substantial ( $\geq 50 \%$ ) reduction in tumor blood flow after eight days of pazopanib exposure. Ten patients had $\mathrm{a} \geq 50 \%$ reduction in tumor blood flow by day 22 .

\section{Phase II trial in advanced RCC patients}

In order to evaluate further the efficacy of pazopanib and explore potential toxicities in patients with advanced/ metastatic RCC, a multicenter, randomized, discontinuation study was conducted. ${ }^{18}$ Patients with metastatic or locally recurrent clear cell RCC (predominantly clear cell features on histology), were either treatment-naïve or treated with cytokine therapy, and who had measurable disease defined by Response Evaluation Criteria In Solid Tumors (RECIST) were included in this study. In this open-label trial, pazopanib $800 \mathrm{mg}$ /day was administered orally. The trial was initially designed as a randomized discontinuation study, with all patients receiving pazopanib and those with stable disease randomized to receive either continued drug or matched placebo. However, planned interim analysis conducted after the first 60 patients had reached 12 weeks, showed that the response rate was $38 \%$ and therefore further randomization was halted and all patients were assigned to pazopanib.

This Phase II study enrolled 225 eligible patients, with 55 patients having stable disease at week 12 and undergoing randomization. The overall response rate for patients treated with pazopanib was $35 \%$, and response rates were similar whether patients were treatment-naïve or cytokinepretreated. The median duration of response was found to be 68 weeks and the median progression-free survival (PFS) was 52 weeks (95\% confidence interval [CI] 44-60 weeks). The most common adverse effects included fatigue, nausea, hair depigmentation, and hypertension. The most common 
laboratory adverse events included elevation of alanine aminotransferase and aspartate aminotransferase. Grade 3 or 4 adverse events included hypertension, transaminase elevation, diarrhea, and fatigue. Dose reduction was performed in 31\% of patients (dose level 1 was $400 \mathrm{mg}$ daily) and $50 \%$ of these patients were able to increase back up to the target dose. Based on these efficacy and safety data, a large Phase III trial of pazopanib in advanced RCC patients was performed.

\section{Phase III study of pazopanib in advanced RCC patients}

A Phase III multicenter, international, randomized, placebocontrolled study of pazopanib in patients with advanced/ metastatic RCC patients has been conducted and recently reported. ${ }^{19}$ Enrollment criteria for this study was similar to those in the Phase II study, with patients having clear cell or predominantly clear cell morphology and either treatmentnaïve or a single prior cytokine-based therapy being eligible for participation. Patients were stratified by Eastern Cooperative Oncology Group (ECOG) performance status (0 versus 1), prior nephrectomy, and prior treatment (naïve versus cytokine). Patients were randomized 2:1 to receive either pazopanib or matching placebo. Patients randomized to the study drug arm received pazopanib $800 \mathrm{mg} /$ day orally. The primary endpoint of the study was PFS, with secondary endpoints including overall survival, overall response rate, and safety. Additionally quality of life analyses were performed. In this study 435 patients were randomized (290 pazopanib versus 145 placebo). Most of these patients had previously undergone nephrectomy (88\%) and were treatment-naïve (54\%).

The median PFS was found to be 9.2 months versus 4.2 months in the treatment group compared with placebo with a hazards ratio (HR) of 0.46 (95\% CI 0.34-0.62, $P<0.0001)$. When analyzed based on prior therapy, the median PFS for patients who were treatment-naïve was 11.1 months (versus 2.8 months for placebo, HR $0.40, P<0.0001$ ) compared with 7.4 months in those that were cytokine-pretreated (versus 4.3 months for placebo, HR 0.54, $P<0.001$ ). The overall response rate for the pazopanib-treated group was $30 \%$ (95\% CI 25.1\%-35.6\%) based on independent review. The treatment-naïve subset had an overall response rate of $32 \%$ compared with $29 \%$ for the cytokine-treated subset. The median duration of response was found to be 58.7 weeks. At the time of publication, overall survival data were not reported due to lack of maturity.

Adverse events were similar to that seen in the Phase I and II trials, with the most common adverse events being diarrhea, hypertension, hair depigmentation, nausea, anorexia, and vomiting (see Table 2). Of note, most adverse events were Grade 1 or 2 . Grade 3 and 4 adverse events were seen in the pazopanib-treated group with a frequency of $33 \%$ and $7 \%$, respectively, compared with the placebo group with a frequency of $14 \%$ and $6 \%$, respectively. The most common Grade 3 or 4 adverse events in the pazopanib group were hypertension (4\%) and diarrhea (4\%). Of note, arterial thrombotic events were seen in $3 \%$ of the pazopanib-treated patients (myocardial infarction $2 \%$, cerebrovascular events $<1 \%$, and transient ischemic attacks $<1 \%$ ) compared with none in the placebo arm. In terms of laboratory abnormalities, most were Grade 1 or 2, with the most common being alanine aminotransferase or aspartate aminotransferase elevation. A quality of life assessment was also included in this trial and, interestingly, pazopanib was found to show no difference in terms of tolerability compared with placebo.

Based on the safety and efficacy of pazopanib in this clinical trial, pazopanib was approved for use in advanced RCC patients by the FDA in October 2010.

Table 2 Toxicities of pazopanib from the Phase III study in renal cell carcinoma $(n=290)$ which occurred at a rate of $10 \%$ or more. The toxicities are arranged in order of the most common adverse (any grade) to the least common. Grade 3/4 toxicities with frequency of occurrence are listed as well

\begin{tabular}{|c|c|c|c|c|}
\hline \multirow[t]{2}{*}{ Adverse events } & \multicolumn{2}{|l|}{ Any grade } & \multicolumn{2}{|l|}{ Grade 3/4 } \\
\hline & Number & $\%$ & Number & $\%$ \\
\hline ALT elevation & 152 & 53 & 35 & 12 \\
\hline AST elevation & 152 & 53 & 23 & 8 \\
\hline Diarrhea & 150 & 52 & 11 & 4 \\
\hline Hypertension & 115 & 40 & 13 & 4 \\
\hline Hyperglycemia & 115 & 41 & 2 & I \\
\hline Hair depigmentation & 109 & 38 & 1 & 0 \\
\hline Leukopenia & 103 & 37 & 0 & 0 \\
\hline Total bilirubin elevation & 102 & 36 & 9 & 3 \\
\hline Hypophosphatemia & 95 & 34 & 11 & 4 \\
\hline Neutropenia & 94 & 34 & 4 & I \\
\hline Hypocalcemia & 91 & 33 & 8 & 3 \\
\hline Thrombocytopenia & 89 & 32 & 3 & I \\
\hline Hyponatremia & 86 & 31 & 15 & 5 \\
\hline Lymphocytopenia & 86 & 31 & 12 & 4 \\
\hline Nausea & 74 & 26 & 2 & I \\
\hline Anorexia & 65 & 22 & 6 & 2 \\
\hline Vomiting & 61 & 21 & 7 & 2 \\
\hline Fatigue & 55 & 19 & 7 & 2 \\
\hline Hypoglycemia & 47 & 17 & I & 0 \\
\hline Asthenia & 41 & 14 & 8 & 3 \\
\hline Abdominal pain & 32 & 11 & 6 & 2 \\
\hline Hypomagnesemia & 31 & 11 & 9 & 3 \\
\hline Headache & 30 & 10 & 0 & 0 \\
\hline
\end{tabular}

Abbreviations: ALT, alanine aminotransferase; AST, aspartate aminotransferase. 


\section{Placement of pazopanib among other available treatment options}

Pazopanib is the latest addition to the armamentarium of therapies for metastatic RCC, making a total of six new treatment options in the past four years. Because of the many options which are available to the practitioner, it is helpful to understand the manner in which each of these drugs was evaluated in the clinical trial setting. Additionally, it is important to consider potential side effects of the drugs when determining appropriate therapy for each individual patient. A summary of pivotal Phase III data is shown in Table 3.

Sorafenib, a multitargeted TKI, was the first agent to gain approval in December 2005. Sorafenib potently inhibits VEGFR 1-3, PDGFR- $\alpha$ and - $\beta$, RAF, FLT-3, and c-kit. Sorafenib was compared with placebo in a Phase III randomized trial in metastatic RCC patients previously treated with cytokine therapy and was demonstrated to have a PFS of 5.5 months compared with 2.8 months for placebo. ${ }^{20}$ Common adverse events were fatigue, diarrhea, rash, and hand-foot syndrome. In a Phase II analysis of sorafenib to interferon in the treatment-naïve setting a similar PFS was seen (5.7 versus 5.6 months). Improvements in response rate and quality of life outcomes were noted in the group receiving sorafenib. Given the findings from the Phase III trial, there is Level 1 evidence for the use of sorafenib after cytokine therapy, although sorafenib is commonly employed as at least second-line therapy following initial sunitinib failure.

Sunitinib, a multitargeted TKI which inhibits VEGFR1-3, PDGFR- $\alpha$ and $-\beta$, FLT- 3 , and c-kit, gained approval in January 2006 after results of a Phase III trial in treatment-naïve metastatic RCC patients showed a PFS of 11 months versus only 5 months for placebo. ${ }^{21}$ Response rates for sunitinib were $31 \%$ compared with $6 \%$ for placebo. Common side effects included diarrhea, fatigue, nausea, hypertension, and handfoot syndrome. No overall survival advantage was seen in the sunitinib arm, which was attributed to the high rate of crossover or subsequent treatment with targeted therapies for those patients progressing on the interferon arm. ${ }^{22}$ Sunitinib has become the most commonly employed agent in the first-line treatment of RCC due to the findings of this pivotal trial.

Temsirolimus which inhibits mTOR was approved in May 2007 for metastatic RCC after a Phase III trial in patients with metastatic RCC and poor risk features showed benefit compared with interferon in the first-line setting. ${ }^{23}$ This three-armed trial evaluated temsirolimus as a single agent versus interferon versus an arm using a combination of the two agents. An overall survival benefit was seen in the temsirolimus group, with a median survival of 10.9 months compared with 7.3 months in the interferon group. There was no advantage seen in the combination arm. Adverse events commonly attributed to temsirolimus include fatigue, anemia, hyperlipidemia, and hyperglycemia. Due to these findings, temsirolimus is seen as a reasonable first-line option for patients with poor risk factors as defined by the Motzer criteria. ${ }^{24}$

Everolimus, an orally bioavailable mTOR inhibitor which acts in a similar fashion as temsirolimus, was studied in a population of metastatic RCC patients who had progressed on sunitinib, sorafenib, or both, and was approved after showing improved PFS in this population compared with placebo (4.9 versus 1.9 months) ${ }^{25,26}$ The side effect profile of everolimus is similar to that of temsirolimus, with common adverse events including fatigue, rash, stomatitis, anemia,

Table 3 Results from Phase III trials of currently approved agents for the treatment of renal cell carcinoma

\begin{tabular}{|c|c|c|c|c|c|}
\hline Study agent & Class & Comparator & Setting & Primary outcome & $\begin{array}{l}\text { Overall survival } \\
\text { benefit }\end{array}$ \\
\hline Sorafenib & VEGF TKI & Placebo & Cytokine-pretreated & $\begin{array}{l}\text { Improved PFS } \\
\text { ( } 5.5 \text { versus } 2.8 \text { months) }\end{array}$ & No \\
\hline Sunitinib & VEGF TKI & Interferon & Treatment-naïve & $\begin{array}{l}\text { Improved PFS } \\
\text { (II versus } 5 \text { months) }\end{array}$ & No \\
\hline Temsirolimus & mTOR inhibitor & Interferon & Treatment-naïve & $\begin{array}{l}\text { Improved OS (I0.9 } \\
\text { versus } 7.3 \text { months) }\end{array}$ & Yes \\
\hline Everolimus & mTOR inhibitor & Placebo & Prior TKI & $\begin{array}{l}\text { Improved PFS } \\
\text { ( } 4.9 \text { versus } 1.9 \text { months) }\end{array}$ & No \\
\hline Bevacizumab-interferon & $\begin{array}{l}\text { Monoclonal } \\
\text { antibody to VEGF }\end{array}$ & Interferon & Treatment-naïve & $\begin{array}{l}\text { Improved PFS } \\
\text { (AVOREN, } 10.2 \text { versus } \\
5.4 \text { months; CALGB, } \\
8.5 \text { versus } 5.2 \text { months) }\end{array}$ & No \\
\hline Pazopanib & VEGF TKI & Placebo & $\begin{array}{l}\text { Treatment-naïve or } \\
\text { cytokine-pretreated }\end{array}$ & $\begin{array}{l}\text { Improved PFS } \\
\text { ( } 9.2 \text { versus } 4.2 \text { months) }\end{array}$ & Data immature \\
\hline
\end{tabular}

Abbreviations: CALGB, Cancer and Leukemia Group B; VEGF, vascular endothelial growth factor; TKI, tyrosine kinase inhibitor; PFS, progression-free survival; OS, overall survival. 
hyperlipidemia, and hyperglycemia. Of note, a noninfectious pneumonitis was seen in $8 \%$ of patients, with Grade 3 pneumonitis in 3\%. This toxicity is felt to be a unique mTOR inhibitor class effect. This is the first Phase III trial showing benefit following TKI failure and should be considered an option for patients who have become TKI-refractory.

Finally, bevacizumab was approved in combination with interferon after two Phase III studies showed that the combination was superior to interferon alone in treatment-naïve metastatic RCC patients. ${ }^{27,28}$ In AVOREN, a Phase III study in treatment-naïve patients, patients receiving bevacizumab-interferon therapy had an improved PFS compared with interferon alone (10.2 months versus 5.4 months). Overall survival from this trial was recently reported and showed no statistically improved survival for the bevacizumab arm. ${ }^{29}$ This effect has been similarly attributed to the addition of more effective therapy to the interferon arm upon progression. A Phase III Cancer and Leukemia Group B (CALGB) study in patients with similar disease also showed improvement in PFS for the combination arm (8.5 months versus 5.2 months). Common side effects of the bevacizumab combination included fatigue, hypertension, and proteinuria.

Table 4 shows placement of the agents according to Level 1 evidence. Based on the previously mentioned Phase III studies, agents which have a high level of evidence for use in good- or intermediate-risk metastatic RCC patients in the treatment-naïve setting would be sunitinib, bevacizumab-interferon, and pazopanib. In patients with poor-risk features, temsirolimus is the only agent to show survival benefit in the front-line setting. For patients who have received prior cytokine therapy, sorafenib or pazopanib have similar high level evidence. In patients who have progressed on TKIs, everolimus has shown benefit. Although these trials give the clinical practitioner a basic framework for how to consider use of these agents in the practical setting,

Table 4 Level I evidence for use of molecularly targeted agents in renal cell carcinoma showing potential treatment settings and agents which have a high level of clinical evidence supporting their use

\begin{tabular}{ll}
\hline Treatment setting & $\begin{array}{l}\text { Agents with high } \\
\text { level of evidence }\end{array}$ \\
\hline Treatment-naïve, good- or intermediate-risk & $\begin{array}{l}\text { Sunitinib } \\
\text { Bevacizumab-interferon }\end{array}$ \\
& pazopanib \\
Treatment-naïve, poor-risk & Temsirolimus \\
Cytokine-refractory & Sorafenib \\
Prior VEGF inhibitor or VEGF-refractory & pazopanib \\
Prior mTOR inhibitor & $?$ \\
\hline
\end{tabular}

Abbreviation: VEGF, vascular endothelial growth factor. our understanding of the optimal sequence of these therapies remains limited. However, a variety of clinical trials are being conducted which will expand our knowledge on optimal sequences and combinations of these therapies.

One important Phase III clinical trial which has recently closed to accrual is a front-line study which is randomizing metastatic RCC patients to either pazopanib or sunitinib. For the past four years, sunitinib has been the standard first-line option for metastatic RCC patients. However, with similar PFS outcomes in Phase II and III studies as that seen with sunitinib, this international, multicenter trial is designed to show that pazopanib is not inferior to sunitinib. If the primary endpoint of PFS is similar in this trial, then the secondary endpoints of toxicity and quality of life may help identify which of these agents should be considered the optimal first-line choice.

\section{Role of pazopanib in the adjuvant setting}

Several international, multicenter, randomized studies are currently being conducted evaluating the role of VEGF receptor TKIs in the adjuvant setting. Due to the increasing risk of incurable recurrence with increasing tumor stage, ${ }^{30,31}$ the incorporation of an effective adjuvant systemic therapy following surgical resection has been a long sought-after goal. Prior efforts to improve recurrence risk following surgical resection involved the use of cytokine-based adjuvant treatments and this approach was unsuccessful. ${ }^{32,33}$ Currently, three studies evaluating VEGF-targeted adjuvant treatments are being conducted. The ASSURE (Adjuvant Sorafenib or Sunitinib for Unfavorable Renal Carcinoma) trial is a randomized cooperative group study evaluating the adjuvant use of sorafenib or sunitinib versus placebo in RCC patients after they have undergone resection of localized disease (clear cell or non-clear cell allowed). The primary endpoint of this study is disease-free survival. The S-TRAC (Sunitinib Treatment of Renal Adjuvant Cancer) trial is a two-armed trial comparing one year of sunitinib therapy versus placebo in patients with resected localized clear cell RCC. Finally, in a similar manner, the SORCE trial (a Phase III randomized double-blind study comparing SOrafenib with placebo in patients with Resected primary renal CEll carcinoma) is currently comparing adjuvant sorafenib for one year versus sorafenib for three years versus matching placebos in patients with resected clear cell RCC or non-clear cell RCC. Everolimus will also be explored in the adjuvant setting versus placebo in a Southwest Oncology Group trial. 
Pazopanib's role as an adjuvant therapy following nephrectomy will also be explored in a Phase III randomized trial. In this trial, approximately 1500 patients with Stage T2 (Grade 3 or 4), T3, T4, or TxN1 clear cell RCC will undergo randomization to either pazopanib versus placebo following surgical resection. Pazopanib $800 \mathrm{mg}$ daily will be administered for one year in the treatment arm. The primary endpoint will be recurrence-free survival, with the secondary endpoints including overall survival.

\section{Role of pazopanib in sequential or combination therapy Sequential therapy}

During the course of first-line VEGF-targeted therapy, the RCC tumor will eventually become resistant to treatment, requiring a switch to a different agent. With the currently available options, this second-line treatment consists of either a different VEGF-targeted therapy or an mTOR inhibitor. A large amount of data has been collected showing that crossresistance is uncommon with sunitinib and sorafenib used in a sequential manner. Similarly, sunitinib has shown activity after bevacizumab and axitinib (a potent VEGF receptor inhibitor and TKI) and in sorafenib-treated RCC patients. ${ }^{34}$ Additionally, everolimus was approved based on its activity in patients who had failed one or two VEGF-targeted TKIs. Unfortunately, no data exist which establish what the optimal sequence of therapies should be, and it may be that the best sequencing of regimens will differ among the spectrum of RCC patients as we learn more about potential biologic subsets within this population.

Currently, several large clinical trials are ongoing which will evaluate therapeutic sequencing. The Phase III RECORD (REnal Cell cancer treatment with Oral RAD001 given Daily)-3 trial will evaluate the sequence of sunitinib followed by everolimus versus everolimus followed by sunitinib. Another trial which has recently completed accrual is the AXIS trial, which is exploring the second-line efficacy of sorafenib versus axitinib following failure of prior sunitinib or mTOR inhibitor. The temsirolimus (Torisel ${ }^{\circledR}$ ) 404 will determine the superiority of temsirolimus or sorafenib after firstline TKI failure. In terms of pazopanib, it is currently being evaluated as a second-line agent in a single-institution Phase II trial (NCT00731211) in RCC patients who have failed either sunitinib or bevacizumab in the first-line setting.

\section{Combination therapy}

Although there is a rationale for combining targeted agents in the hope of producing improved outcomes, it is unclear if this approach is superior than sequential single agent therapies. Attempts to combine sunitinib with bevacizumab or temsirolimus have resulted in too much toxicity. However, given pazopanib's side effect profile, perhaps it will be more amenable to attempts at combination. Several trials are currently evaluating combination regimens. These include the RECORD-2 trial which is evaluating bevacizumab-interferon versus bevacizumab-everolimus. Similarly, the INTORACT (INvestigation of TORisel and Avastin Combination Therapy) trial is comparing bevacizumab-interferon versus bevacizumab-temsirolimus. In a more complex four-armed study, the BeST trial (ECOG 2804) is evaluating bevacizumab alone versus bevacizumab-temsirolimus, bevacizumabsorafenib, and sorafenib-temsirolimus. Pazopanib is currently being evaluated in a single institution Phase II study in combination with bevacizumab (NCT00992121), with endpoints focused on tumor response and pharmacodynamic correlates. Pazopanib is also being evaluated in a variety of different tumor types in combination with a variety of different agents, such as ixabepilone, lapatinib, liposomal doxorubicin, paclitaxel, temsirolimus, gemcitabine, and navelbine.

\section{Conclusion}

Pazopanib is an orally bioavailable multitargeted TKI which targets and potently inhibits VEGF-R1-3, PDGFR- $\alpha$ and $-\beta$, and c-kit. Based on its preclinical activity in RCC models, it was tested in a Phase I trial and showed tolerability with optimal dosing at $800 \mathrm{mg}$ daily. Additionally, it has shown clinical efficacy for patients with metastatic clear cell RCC in large Phase II and Phase III clinical trials compared with placebo. Based on these studies, pazopanib was approved for use in metastatic RCC in October 2009.

Pazopanib is felt to have a favorable toxicity profile with apparently less common development of hand-foot syndrome and cytopenia compared with its predecessors. The lack of difference in quality of life assessment between patients taking pazopanib and placebo highlights this favorable toxicity profile. One potential explanation for the lack of cytopenia is that pazopanib is not a potent inhibitor of Flt-3. Additionally, pazopanib appears to have a higher frequency of liver enzyme elevation, although this side effect was shown to be manageable in study patients. In a recent publication, an exploratory analysis of patients in both the Phase II and Phase III RCC trials was conducted to explore this side effect of pazopanib further. In this analysis, in those patients with hyperbilirubinemia ( $>1.5 \times$ upper limit of normal), $84 \%$ had genetic polymorphisms consistent with homozygous or heterozygous Gilbert's syndrome. ${ }^{35}$ 
Based on cross-comparison of the Phase III trials involving sunitinib and bevacizumab, pazopanib showed a similar degree of response and PFS. Currently, a large multicenter Phase III trial comparing sunitinib with pazopanib in treatment-naïve patients is ongoing, and should shed light on the potential equivalence of pazopanib and sunitinib. Pazopanib will also be evaluated in the adjuvant setting following surgical resection of localized RCC. Key questions regarding the proper sequence of targeted agents and the role of combinations of targeted agents still exist. Currently, pazopanib is considered a valid treatment option for metastatic RCC patients in need of front-line therapy based on a high level of clinical evidence. The role which pazopanib will play in sequencing or combination regimens or in the adjuvant setting, however, still needs to be further explored.

\section{Disclosure}

Dr. Sonpavde is a speaker for, and has received honoraria from, GSK.

\section{References}

1. Bukowski RM. Cytokine therapy for metastatic renal cell carcinoma. Semin Urol Oncol. 2001;19(2):148-154.

2. Turner KJ, Moore JW, Jones A, et al. Expression of hypoxia-inducible factors in human renal cancer: Relationship to angiogenesis and to the von Hippel-Lindau gene mutation. Cancer Res. 2002;62(10): 2957-2961.

3. Gruber M, Simon MC. Hypoxia-inducible factors, hypoxia, and tumor angiogenesis. Curr Opin Hematol. 2006;13(3):169-174.

4. Tsuzuki Y, Fukumura D, Oosthuyse B, Koike C, Carmeliet P, Jain RK. Vascular endothelial growth factor (VEGF) modulation by targeting hypoxia-inducible factor-1alpha - hypoxia response element - VEGF cascade differentially regulates vascular response and growth rate in tumors. Cancer Res. 2000;60(22):6248-6252.

5. Fukumura D, Xavier R, Sugiura T, et al. Tumor induction of VEGF promoter activity in stromal cells. Cell. 1998;94(6):715-725.

6. Hippenstiel S, Krull M, Ikemann A, Risau W, Clauss M, Suttorp N. VEGF induces hyperpermeability by a direct action on endothelial cells. Am J Physiol. 1998;274(5 Pt 1):L678-L684.

7. Carmeliet P. VEGF as a key mediator of angiogenesis in cancer. Oncology. 2005;69(Suppl 3):4-10.

8. Edgren M, Lennernas B, Larsson A, Nilsson S. Serum concentrations of VEGF and b-FGF in renal cell, prostate and urinary bladder carcinomas. Anticancer Res. 1999;19(1B):869-873.

9. Clifford SC, Prowse AH, Affara NA, Buys CH, Maher ER. Inactivation of the von Hippel-Lindau (VHL) tumour suppressor gene and allelic losses at chromosome arm $3 \mathrm{p}$ in primary renal cell carcinoma: Evidence for a VHL-independent pathway in clear cell renal tumorigenesis. Genes Chromosomes Cancer. 1998;22(3):200-209.

10. Forsythe JA, Jiang BH, Iyer NV, et al. Activation of vascular endothelial growth factor gene transcription by hypoxia-inducible factor $1 . \mathrm{Mol} \mathrm{Cell}$ Biol. 1996;16(9):4604-4613.

11. Kim WY, Kaelin WG. Role of VHL gene mutation in human cancer. J Clin Oncol. 2004;22(24):4991-5004.

12. Yamakawa M, Liu LX, Belanger AJ, et al. Expression of angiopoietins in renal epithelial and clear cell carcinoma cells: Regulation by hypoxia and participation in angiogenesis. Am J Physiol Renal Physiol. 2004; 287(4):F649-F657.

13. Rini BI. Vascular endothelial growth factor-targeted therapy in metastatic renal cell carcinoma. Cancer. 2009;115(Suppl 10):2306-2312.
14. Hudson CC, Liu M, Chiang GG, et al. Regulation of hypoxia-inducible factor 1alpha expression and function by the mammalian target of rapamycin. Mol Cell Biol. 2002;22(20):7004-7014.

15. Harris PA, Boloor A, Cheung M, et al. Discovery of 5-[[4-[(2,3dimethyl-2H-indazol-6-yl)methylamino]-2-pyrimidinyl]amino]-2-m ethyl-benzenesulfonamide (Pazopanib), a novel and potent vascular endothelial growth factor receptor inhibitor. JMed Chem. 2008;51(15): $4632-4640$.

16. Kumar R, Knick VB, Rudolph SK, et al. Pharmacokineticpharmacodynamic correlation from mouse to human with pazopanib, a multikinase angiogenesis inhibitor with potent antitumor and antiangiogenic activity. Mol Cancer Ther. 2007;6(7):201-221.

17. Hurwitz HI, Dowlati A, Saini S, et al. Phase I trial of pazopanib in patients with advanced cancer. Clin Cancer Res. 2009;15(12):4220-4227.

18. Hutson TE, Davis ID, Machiels JP, et al. Efficacy and safety of pazopanib in patients with metastatic renal cell carcinoma. JClin Oncol. 2010;20;28(3):475-480.

19. Sternberg CN, Davis ID, Mardiak J, et al. Pazopanib in locally advanced or metastatic renal cell carcinoma: Results of a randomized Phase III trial. J Clin Oncol. 2010;28(6):1061-1068.

20. Escudier B, Eisen T, Stadler WM, et al. Sorafenib in advanced clear-cell renal-cell carcinoma. $N$ Engl J Med. 2007;356(2):125-134.

21. Motzer RJ, Hutson TE, Tomczak P, et al. Sunitinib versus interferon alfa in metastatic renal-cell carcinoma. N Engl J Med. 2007;356(2):115-124.

22. Motzer RJ, Hutson TE, Tomczak P, et al. Overall survival and updated results for sunitinib compared with interferon alfa in patients with metastatic renal cell carcinoma. J Clin Oncol. 2009;27(22): 3584-3590.

23. Hudes G, Carducci M, Tomczak P, et al. Temsirolimus, interferon alfa, or both for advanced renal-cell carcinoma. NEngl J Med. 2007;356(22): 2271-2281.

24. Motzer RJ, Mazumdar M, Bacik J, Berg W, Amsterdam A, Ferrara J. Survival and prognostic stratification of 670 patients with advanced renal cell carcinoma. J Clin Oncol. 1999;17(8):2530-2540.

25. Motzer RJ, Escudier B, Oudard S, et al. Efficacy of everolimus in advanced renal cell carcinoma: A double-blind, randomised, placebocontrolled phase III trial. Lancet. 2008;372(9637):449-456.

26. Kay A, Motzer R, Figlin R, et al. Updated data from a phase III randomized trial of everolimus (RAD001) versus PBO in metastatic renal cell carcinoma (mRCC). ASCO Genitourinary Cancer Symposium. 2009 Feb 26-28, Orlando, FL.

27. Escudier B, Pluzanska A, Koralewski P, et al. Bevacizumab plus interferon alfa-2a for treatment of metastatic renal cell carcinoma: A randomised, double-blind Phase III trial. Lancet. 2007;370(9605):2103-2111.

28. Rini BI, Halabi S, Rosenberg JE, et al. Bevacizumab plus interferon alfa compared with interferon alfa monotherapy in patients with metastatic renal cell carcinoma: CALGB 90206. J Clin Oncol. 2008;26(33):5422-5428.

29. Escudier B, Bellmunt J, Negrier S, et al. Phase III trial of bevacizumab plus interferon alfa-2a in patients with metastatic renal cell carcinoma (AVOREN): Final analysis of overall survival. J Clin Oncol. 2010;28(13):2144-2150.

30. Lerner SE, Hawkins CA, Blute ML, et al. Disease outcome in patients with low stage renal cell carcinoma treated with nephron sparing or radical surgery. J Urol. 1996;155(6):1868-1873.

31. Frank I, Blute ML, Leibovich BC, Cheville JC, Lohse CM, Zincke H. Independent validation of the 2002 American Joint Committee on cancer primary tumor classification for renal cell carcinoma using a large, single institution cohort. J Urol. 2005;173(6):1889-1892.

32. Clark JI, Atkins MB, Urba WJ, et al. Adjuvant high-dose bolus interleukin-2 for patients with high-risk renal cell carcinoma: A cytokine working group randomized trial. J Clin Oncol. 2003;21(16): 3133-3140.

33. Messing EM, Manola J, Wilding G, et al. Phase III study of interferon alfa-NL as adjuvant treatment for resectable renal cell carcinoma: An Eastern Cooperative Oncology Group/Intergroup trial. J Clin Oncol. 2003;21(7):1214-1222. 
34. Sablin MP, Negrier S, Ravaud A, et al. Sequential sorafenib and sunitinib for renal cell carcinoma. J Urol. 2009;182(1):29-34; discussion 34.

35. Xu CF, Reck BH, Xue Z, et al. Pazopanib-induced hyperbilirubinemia is associated with Gilbert's syndrome UGT1A1 polymorphism. Br J Cancer. 2010;27;102(9):1371-1377.

36. Bhargava P, Esteves B, Nosov DA, et al. Updated activity and safety results of a phase II randomized discontinuation trial (RDT) of AV-951, a potent and selective VEGFR1, 2, and 3 kinase inhibitor, in patients with renal cell carcinoma (RCC). J Clin Oncol. 2009;27(15S):Abstr 5032.

37. Hu-Lowe DD, Zou HY, Grazzini ML, et al. Nonclinical antiangiogenesis and antitumor activities of axitinib (AG-013736), an oral, potent, and selective inhibitor of vascular endothelial growth factor receptor tyrosine kinases 1, 2, 3. Clin Cancer Res. 2008;14(22):7272-7283.
38. Mendel DB, Laird AD, Xin X, et al. In vivo antitumor activity of SU11248, a novel tyrosine kinase inhibitor targeting vascular endothelial growth factor and platelet-derived growth factor receptors: Determination of a pharmacokinetic/pharmacodynamic relationship. Clin Cancer Res. 2003;9(1):327-337.

39. Wilhelm SM, Carter C, Tang L, et al. BAY 43-9006 exhibits broad spectrum oral antitumor activity and targets the RAF/MEK/ERK pathway and receptor tyrosine kinases involved in tumor progression and angiogenesis. Cancer Res. 2004;64(19):7099-7109.

\section{Publish your work in this journal}

OncoTargets and Therapy is an international, peer-reviewed, open access journal focusing on the pathological basis of all cancers, potential targets for therapy and treatment protocols employed to improve the management of cancer patients. The journal also focuses on the impact of management programs and new therapeutic agents and protocols on

\section{Dovepress}

patient perspectives such as quality of life, adherence and satisfaction. The manuscript management system is completely online and includes a very quick and fair peer-review system, which is all easy to use. Visit http://www.dovepress.com/testimonials.php to read real quotes from published authors.

Submit your manuscript here: http://www.dovepress.com/oncotargets-and-therapy-journal 